\title{
Large Deflection of Clamped Curved Beam Under Finite Clamping and Different Combinations of Bending-Stretching
}

\author{
Sushanta Ghuku* ${ }^{*}$, Kashinath Saha \\ Department of Mechanical Engineering, Jadavpur University, Kolkata, India \\ E-mail: info.sghuku@gmail.com
}

Received: 22 July 2020; Revised: 11 August 2020; Accepted: 25 August 2020

\begin{abstract}
The paper experimentally and theoretically analyses large deflection behaviour of clamped curved beam subjected to finite clamping and combined bending-stretching loads. The experimental specimen is clamped around central location under vertically concave and convex orientations. For each specimen settings, clamping is done by two different torque values. Application of vertical end loads on the clamped concave and convex systems produces two different combinations of bending and in-plane loadings. Large deflection behaviour of the experimental system is modelled theoretically considering geometric nonlinearities coming from combined bending-stretching, nonuniform curvature and asymmetric geometry. Effect of finite clamping is incorporated in the theoretical model through equivalent additional end loads. Due to the involved geometric nonlinearities, analysis is carried out through variational energy principle based incremental Lagrangian approach in curvilinear system and transformed into global frame. The semi-analytical model is successfully validated by comparing with the experimental results. The combined theoreticalexperimental study addresses practical complication associated with local deformation at boundaries. In addition, the physically plausible theoretical model may be of interest for simulation of many real world structures with complicating system parameters. Moreover, observations on combined effects of curvature, loading combinations and finite clamping may provide reference for design optimization of equivalent engineering structures.
\end{abstract}

Keywords: curved beam, large deflection, finite clamping, combined bending-stretching, variational energy principle, incremental lagrangian

\section{Introduction}

Conventionally beam like flexible structures in engineering applications are designed under prescribed deformation constraints at boundaries [1]. However, many practical members do not follow such classical assumptions and involve complicating effects coming from finite deformation at boundaries. Such deformation dependent boundary conditions of practical structures cause failure of classical models during operating condition [2]. When the structural members undergo large deformation, such non-conventional system parameters dominate their deformation characteristics [3]. In addition, if the structures involve initial curvature, their deformation characteristics become much more complicated due to interaction of several deformation degrees, like, bending, centre line stretching, shear deformation, etc. [4], [5]. Some frequently encountered complicating effects associated with non-conventional boundary conditions are reviewed from the available literature and presented in the next paragraph. Following that a brief review on large deformation

Copyright (C2020 Sushanta Ghuku, et al.

DOI: https://doi.org/10.37256/est.212021548

This is an open-access article distributed under a CC BY license

(Creative Commons Attribution 4.0 International License)

https://creativecommons.org/licenses/by/4.0/ 
characteristics of curved beams together with foundation of related analysis methods is presented in another paragraph.

The most widely used classical boundary conditions for beam bending problems are simple supports and clamped conditions. One major practical complication associated with simple supports is shifting of contact points during large deformation [6]. Due to this relative motion between the structure and its supports, friction force is generated at contacting surface. The friction force imparts in-plane loading on the deforming structure and leads towards mixed displacement-force boundary conditions [7]. Symmetry of beam structure and loading with respect to the supports balances the friction forces at two ends [8]. Whereas, generalised asymmetric geometry and loading increases complications due to imbalance of friction forces at the boundaries [9]. Another practical complication of simple supports is violation of displacement restraint under operating condition [10]. For clamped beam problems, theoretically infinite clamping is assumed at fixed supports. Or in other words, zero displacement and rotation are assumed at clamped ends. However, practically such ideal clamping is not possible. Hence, finite deformation under finite clamping at the clamped end affects deformation characteristics of clamped practical structures [11]. In addition to the frequently encountered simple, clamped and hinged supports, several machine elements in mechanical engineering applications contain rigid links at boundaries [12]. Such combined rigid-flexible structures are subjected to another class of complications due to interactive deformation of flexible member with rigid links [13]. Another frequently encountered complicating effect associated with large framed structures is partial flexibility of connections between their beam and column elements [14]. So called semi-rigid characteristics of such beam-column connections cause failure of design based on classical assumption of rigid or simple connections [15]. The literature survey yields that boundary conditions of simply supported, clamped-clamped, cantilever or any other type of practical structural and machine elements depend on deformation state to some extent. Such deformation dependent local deformations at boundaries are generally modelled using longitudinal [16] and rotational [17] springs at boundaries. For simple geometry and loading conditions, spring elements with linear characteristics effectively capture deformation at boundaries. However, nonlinear springs are required for rigorous modelling of more complicated structures [18].

Large deformation characteristics of initially straight beams with simple loading and boundary conditions are well captured by geometrically nonlinear kinematic setting of the original Euler-Bernoulli model [19]. With increasing complexity in terms of problem parameters, pure bending assumption of such classical nonlinear models causes failure [20]. Out of plane cross-sectional deformation is one of such complicating effect associated with thick beams. Whereas, centre line extensibility dominates large deformation behaviours of slender beams. Deformation characteristics of thick beams with classical problem parameters are generally analysed through Timoshenko beam theory and several other higher order shear deformation theories [21]. Geometrically nonlinear combined bending-stretching models are employed to analyse deformation behaviours of very slender beams [22]. Presence of some initial curvature in beam structures further increases complexity through coupling of different deformation degrees of freedom, like, bending, stretching, shear deformation, cross-sectional warping, torsion, etc. [13], [23]. Simo-Reissner beam model provides the most systematic framework for large deformation analysis of curved beam like structures [5], [24]. Geometrically nonlinear beam models based on Simo-Reissner theory are generally implemented using variational principle either through conventional full domain methods [4], [13] or through discretization of problem domain into finite number of elements [23], [24]. Straight beam elements were previously used extensively for approximating curved beam geometry in finite element analysis. Use of straight elements in large number for approximating curved geometry not only results high computational cost but also arises question on accuracy as well [25]. Development of economically efficient and rigorous curved beam elements has been one of the major focus of engineers for the last few decades [26]. Detailed discussions on theoretical backgrounds of the extensively used large deformation curved beam models are well documented in the papers [27], [28]. Hence, such discussions on large deformation curved beam problems are not repeated here to maintain brevity.

Though large deformation analysis of curved beam has been an active research field for the last few decades, sufficient studies on curved beam problems with complicating effects caused by non-conventional boundary and loading conditions are not found in literature. Most of the reported studies on effects of the non-conventional system parameters deal with initial straight beams. Majority of such reported beam models are developed within pure numerical framework, whereas, analytical treatment of the problems is rare. Moreover, the research area lacks in experimental fidelity as well. One of the rare experimental study on the subject problem dealing with large deformation characteristics of curved beam under finite clamping and combined bending-stretching loads is reported by the authors in a previously 
reported work [29]. The experimental results are first post-processed in the present work to obtain interactive effect of finite clamping with combined loading. Based on the observations, theoretical model of the experimental curved beam system is developed through variational energy principle based incremental Lagrangian approach. Finally the theoretical model is validated with the experimental deflection results and some observations are made. Post-processing of the experimental results, development of theoretical model and the comparison study are presented in the following three sections.

\section{Experimental observations}

Experimental investigations on effects of finite clamping and combined bending-stretching field are carried out through post-processing results of the previously reported work [29]. Master leaf spring is considered as experimental curved beam specimen, which is clamped with vertically concave and convex orientations under 3 and $14 \mathrm{~kg}-\mathrm{m}$ clamping torques for each setting. Photographs of the specimen settings under the two different orientations are shown in Figure 1.
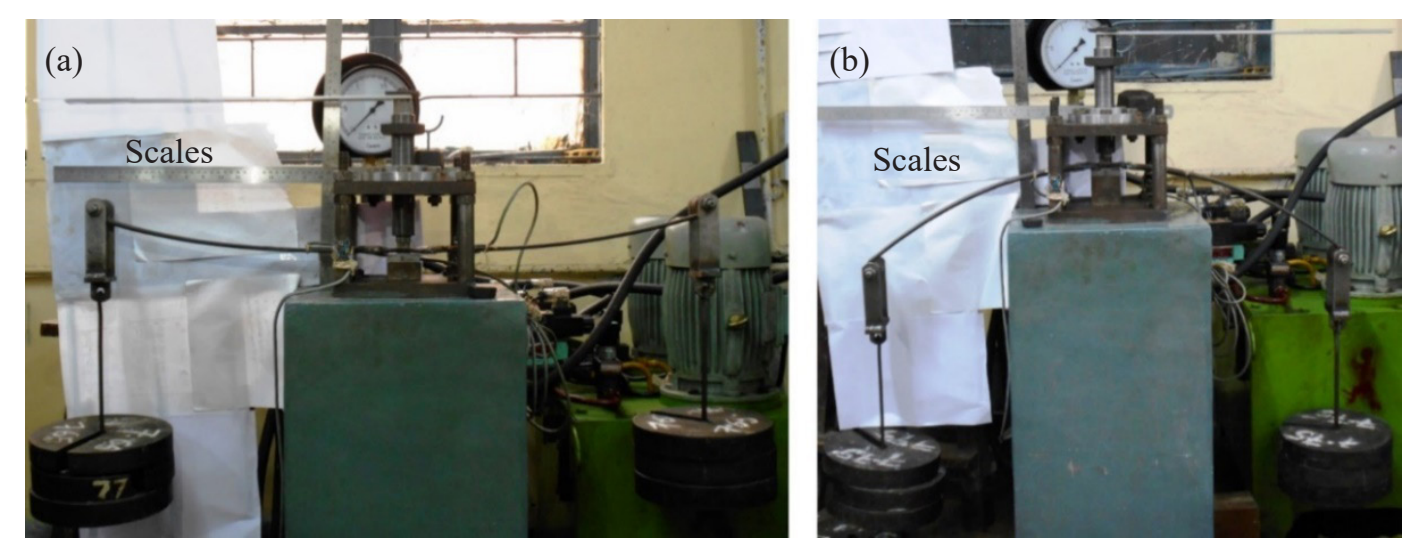

Figure 1. Photographs of the experimental set-up with vertically (a) concave and (b) convex specimen orientations

For each of the curved beam setting under each clamping torque, external loads $\left(F_{W}\right)$ are applied symmetrically at the two eye ends through eight steps of magnitudes 14.42, 90.94, 166.48, 241.52, 317.55, 391.62, 463.23 and 484.81 N. Deflection profiles of the four different loaded curved beam systems are obtained through some direct measurement and image processing techniques. Detailed descriptions of the experimental set-up, measurement techniques and deflection results are already presented in the article ${ }^{[29]}$. Post-processing of the deflection profiles to obtain effects of finite clamping and specimen orientation on deformation characteristics of the curved beam system is presented in the following sub-section.

\subsection{Post-processing of load-deflection results}

From loaded deflection profiles of the curved beam specimen under each of the four settings, deflections of the left and right tips are obtained with respect to undeformed geometry. Due to asymmetry of the specimen geometry about clamping location, left and right tips undergo different deflections under the same applied load $\left(F_{W}\right)$ and they are denoted by $\delta_{L}$ and $\delta_{R}$ respectively. Variations of tip deflections $\delta_{L}$ and $\delta_{R}$ with applied load $F_{W}$ are presented through direct data points (dotted points) and fitted curves (dashed lines) in Figure 2(a1) and (a2) for concave system under $3 \mathrm{~kg}-\mathrm{m}$ clamping torque. Variations of $\delta_{L}$ and $\delta_{R}$ with $F_{W}$ for the concave system under $14 \mathrm{~kg}$-m clamping torque are shown in Figure 2(b1) and (b2). Similar load-deflection plots for the convex curved beam system are shown in Figure 3 following the representation scheme of Figure 2.

Before application of external static loads $\left(F_{W}\right)$, curved beam systems undergo deflections due to application of 
clamping torque only. Such deflections due to clamping only are different for the left tip than those of the right tip due to asymmetric specimen geometry, and denoted by $\delta_{C L}$ and $\delta_{C R}$ respectively. As the tip deflections $\delta_{L}$ and $\delta_{R}$, presented in Figures 2 and 3, are measured with respect to the initial geometry, they consist of deflections due to clamping only $\left(\delta_{C L}\right.$ and $\left.\delta_{C R}\right)$ and deflections due to dead load only $\left(\delta_{W L}\right.$ and $\left.\delta_{W R}\right) . \delta_{L}$ and $\delta_{R}$ axes intercepts of the fitted $F_{W}-\delta_{L}$ and $F_{W}-$ $\delta_{R}$ curves in Figures 2 and 3 obviously give deflections due to clamping only $\left(\delta_{C L}\right.$ and $\left.\delta_{C R}\right)$, as these deflection values correspond zero applied loads $\left(F_{W}\right)$. Numerical values of the deflections $\delta_{C L}$ and $\delta_{C R}$ for the four different curved beam settings are presented in Table 1.
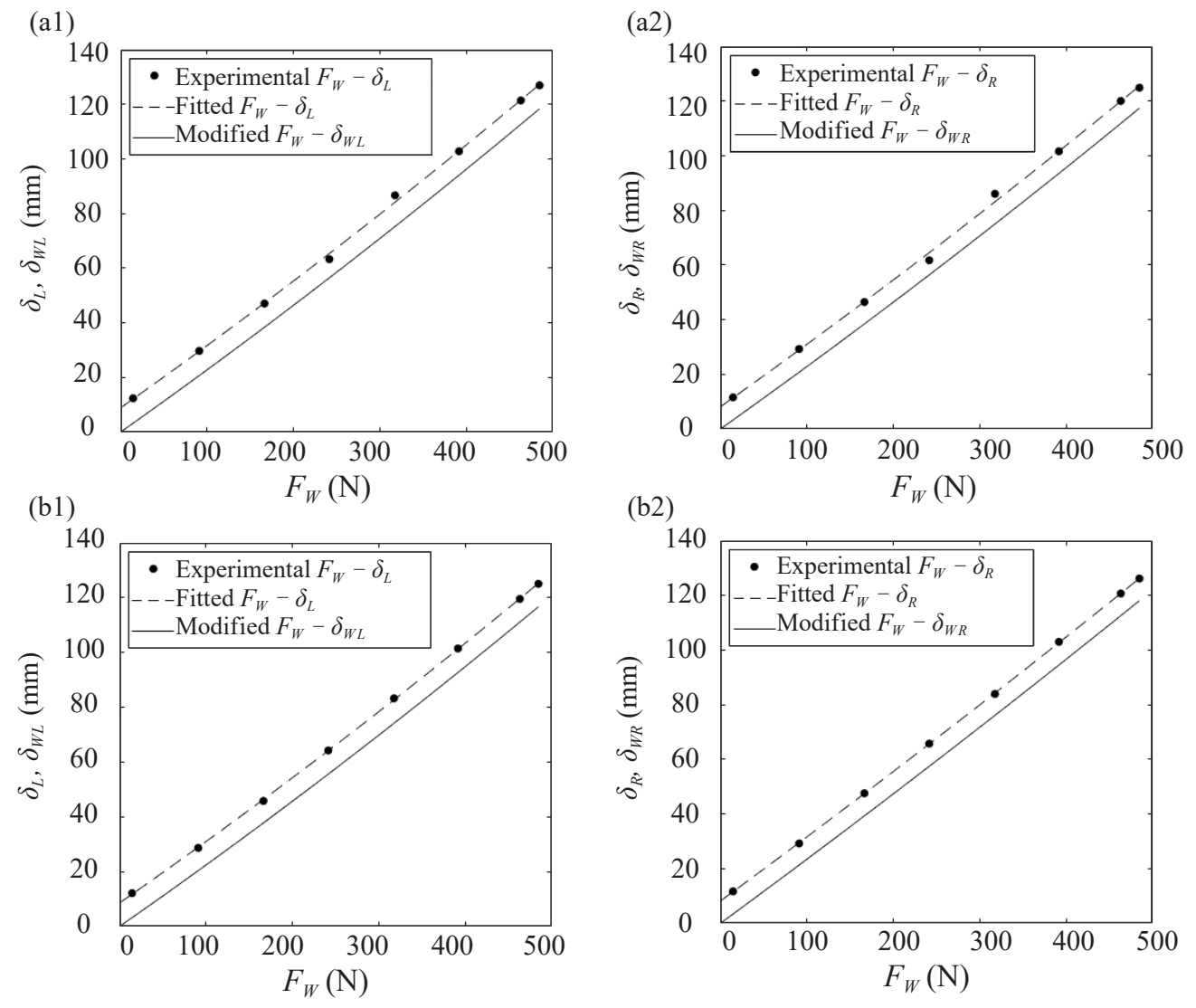

Figure 2. Load-deflection behaviour of (\#1) left and (\#2) right tip for concave set-up under (a\#) $3 \mathrm{~kg}-\mathrm{m}$ and (b\#) $14 \mathrm{~kg}$-m clamping torque

(a1)

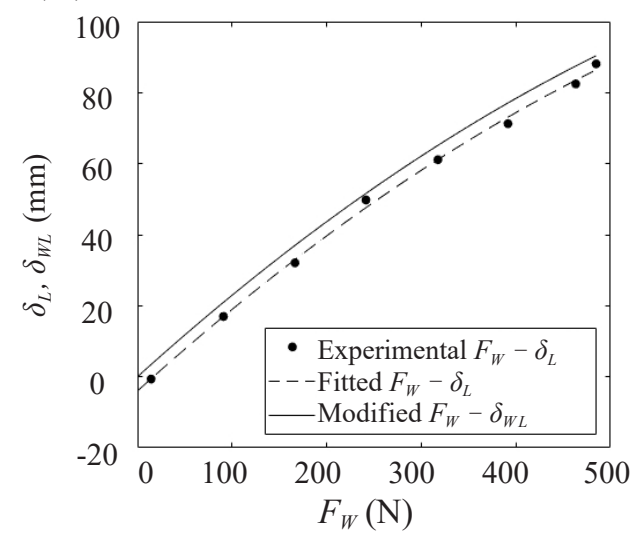

(a2)

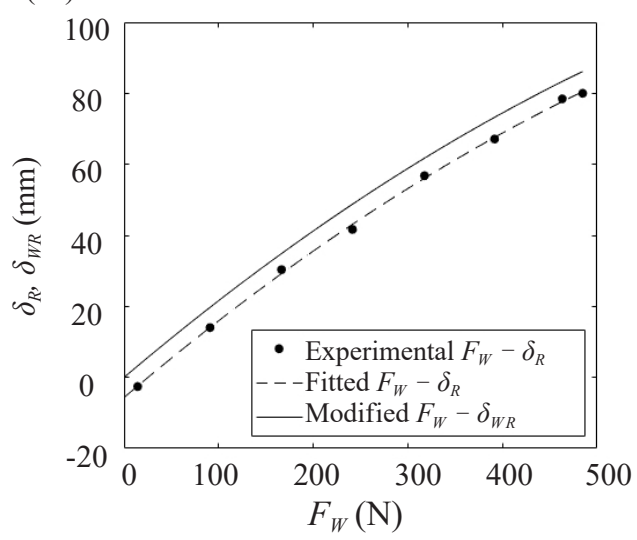



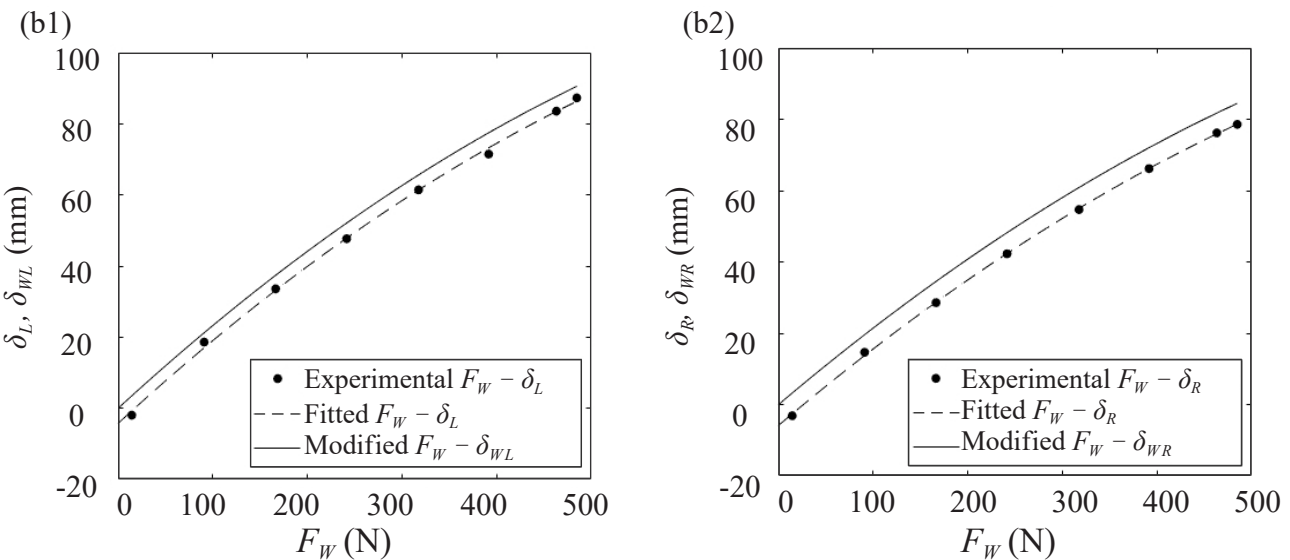

Figure 3. Load-deflection behaviour of (\#1) left and (\#2) right tip for convex set-up under (a\#) $3 \mathrm{~kg}-\mathrm{m}$ and (b\#) $14 \mathrm{~kg}-\mathrm{m}$ clamping torque

Table 1. Tip deflections (mm) of different curved beam systems due to clamping

\begin{tabular}{ccccc}
\hline Measurement & $\begin{array}{c}\text { Concave under } \\
3 \mathrm{~kg}-\mathrm{m} \text { torque }\end{array}$ & $\begin{array}{c}\text { Concave under } \\
14 \mathrm{~kg}-\mathrm{m} \text { torque }\end{array}$ & $\begin{array}{c}\text { Convex under } \\
3 \mathrm{~kg}-\mathrm{m} \text { torque }\end{array}$ & $\begin{array}{c}\text { Convex under } \\
14 \mathrm{~kg}-\mathrm{m} \text { torque }\end{array}$ \\
\hline$\delta_{C L}$ & 8.89 & 8.57 & -4.01 & -4.23 \\
$\delta_{C R}$ & 8.13 & 8.17 & -5.66 & -5.84 \\
\hline
\end{tabular}

Positive values of $\delta_{C L}$ and $\delta_{C R}$ for concave systems clearly indicate that deflections produced by clamping are in the same direction to the defections produced by dead loads $F_{W}$. Whereas, negative values of $\delta_{C L}$ and $\delta_{C R}$ for the convex systems indicate deflections due to clamping are in opposite direction to those due to $F_{W}$. The contradictory deflection patterns under finite clamping show significant effect of specimen orientation or combinations of bending-stretching loads on deformation characteristics. Now the load-deflection curves $F_{W}-\delta_{L}$ and $F_{W}-\delta_{R}$ in Figures 2 and 3 are shifted to pass through origin and the modified curves are presented through solid lines in the figures. The modified loaddeflection curves in Figures 2 and 3 obviously represent variations of deflections due to applied load only $\left(\delta_{W L}\right.$ and $\left.\delta_{W R}\right)$ with applied load $\left(F_{W}\right)$. Corresponding to the tip deflection values of Table 1, load values are obtained from the modified load-deflection curves of Figures 2 and 3. These load values obviously represent equivalent end loads $\left(F_{C L}\right.$ and $\left.F_{C R}\right)$ corresponding to clamping deflections $\left(\delta_{C L}\right.$ and $\left.\delta_{C R}\right)$ and presented in Table 2 .

Table 2. Equivalent end forces $(\mathrm{N})$ of different curved beam systems due to clamping

\begin{tabular}{ccccc}
\hline Loading & $\begin{array}{c}\text { Concave under } \\
3 \mathrm{~kg}-\mathrm{m} \text { torque }\end{array}$ & $\begin{array}{c}\text { Concave under } \\
14 \mathrm{~kg}-\mathrm{m} \text { torque }\end{array}$ & $\begin{array}{c}\text { Convex under } \\
3 \mathrm{~kg}-\mathrm{m} \text { torque }\end{array}$ & $\begin{array}{c}\text { Convex under } \\
14 \mathrm{~kg}-\mathrm{m} \text { torque }\end{array}$ \\
\hline$F_{C L}$ & 39.49 & 38.71 & -16.75 & -17.47 \\
$F_{C R}$ & 35.96 & 35.08 & -25.31 & -26.30 \\
\hline
\end{tabular}

\section{Theoretical model}

The experimental concave and convex physical systems are modelled as clamped curved beams subjected to direct externally applied loads $\left(F_{W}\right)$ and an additional equivalent end loads due to clamping $\left(F_{C L}\right.$ or $\left.F_{C R}\right)$. Initial curvature of the curved beam produces combination of bending and membrane loadings under the total vertical loads $F_{L}=F_{C L}$ $+F_{W}$ and $F_{R}=F_{C R}+F_{W}$ at left and right ends. Moreover due to completely opposite direction of curvatures under concave and convex settings, two different combinations of such bending-stretching fields are developed. In addition to geometric nonlinearity associated with combined bending-stretching kinematics, the curved beam systems also involve 
complicating effects caused by non-uniformity of centre line curvature and asymmetry of geometry about clamping location. In order to capture nonlinear deformation characteristics of the physical systems more rigorously, analysis is carried out through incremental Lagrangian approach. Body fitted curvilinear coordinate system is used as framework for incremental analysis through variational energy balance principle. Geometric specifications of previous incremental step $(i-1)$ is considered as reference for analysis of current step $i$. Origins of the body fitted frame at current $\left(O_{s n}^{i}\right)$ and previous $\left(O_{s n}^{i-1}\right)$ step together with global Cartesian frame $O_{x y}$ are defined at the clamped location. The incremental curved beam models with concave and convex settings are shown with respect to global Cartesian frame $O_{x y}$ in Figure 4.
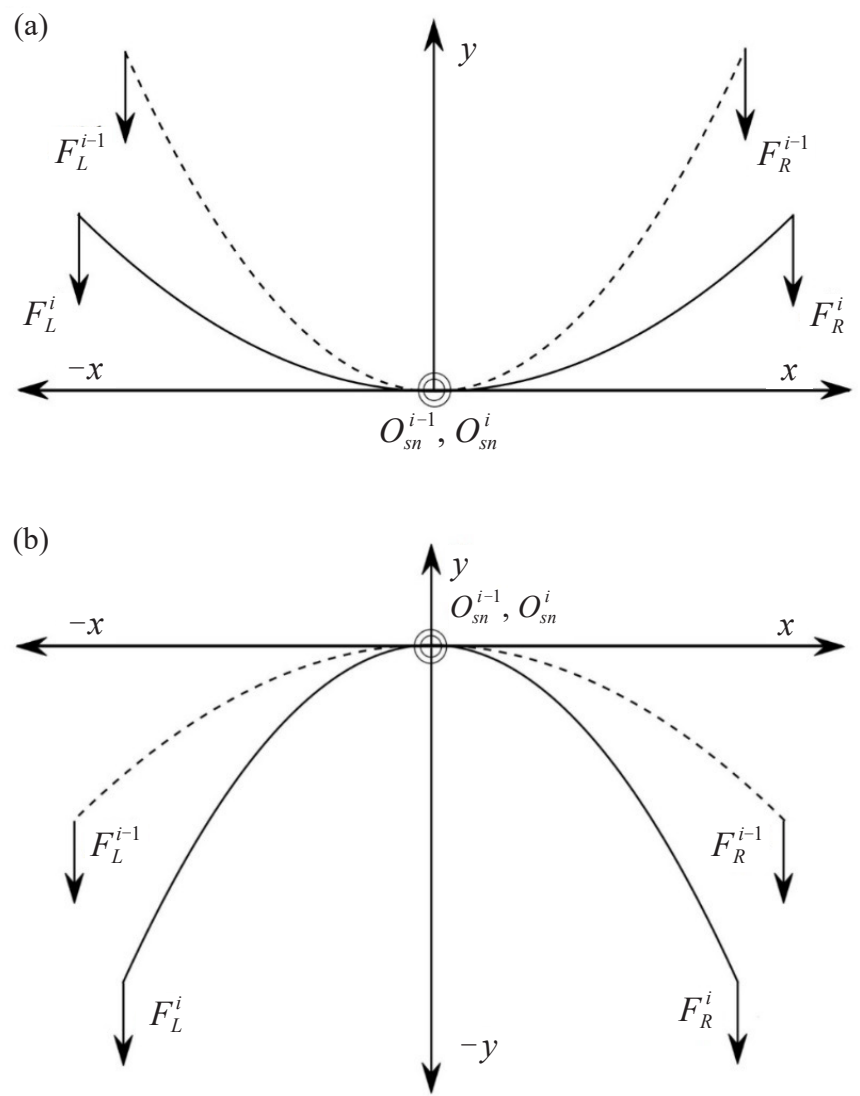

Figure 4. Incremental curved beam model for (a) concave and (b) convex system configuration

The incremental deformation is characterized in global Cartesian frame $(x, y)$ by horizontal $\left(u_{x}\right)$ and vertical $\left(u_{y}\right)$ displacement fields. Whereas, with respect to reference body fitted frame $\left(s^{i-1}, n^{i-1}\right)$, the deformation is characterised by bending $\left(u_{n}\right)$ and stretching $\left(u_{s}\right)$ fields. Boundary conditions of the bending and stretching fields in body embedded frame are prescribed as

$$
\begin{aligned}
& u_{s}=0 \text { at } s^{i-1}=0 \text { and } u_{s}=\text { unknown at } s^{i-1}=-S_{L}^{i-1} \text { and } s^{i-1}=S_{R}^{i-1}, \\
& u_{n}=0 \text { at } s^{i-1}=0 \text { and } u_{n}=\text { unknown at } s^{i-1}=-S_{L}^{i-1} \text { and } s^{i-1}=S_{R}^{i-1} .
\end{aligned}
$$

Transformation relations of the displacement fields between the local and global frames are given by

$$
\left\{\begin{array}{l}
u_{x} \\
u_{y}
\end{array}\right\}=\left[\begin{array}{cc}
\cos \left(\theta^{i-1}\right) & -\sin \left(\theta^{i-1}\right) \\
\sin \left(\theta^{i-1}\right) & \cos \left(\theta^{i-1}\right)
\end{array}\right]\left\{\begin{array}{l}
u_{s} \\
u_{n}
\end{array}\right\} .
$$


In the above equations, $S_{L}^{i-1}$ and $S_{R}^{i-1}$ represent arch lengths of left and right parts of curved beam and $\theta^{i-1}$ represents slope of beam centre line. The superscript $(i-1)$ corresponds reference configuration under previous load step. The notation style of reference configuration by superscript $(i-1)$ is followed hereon throughout the entire document. A detailed list of nomenclature is presented towards the end of the paper. Determination of body fitted displacement fields $u_{s}$ and $u_{n}$ through variational energy principle and subsequent geometry updation using Equation (3) are presented in the following two sub-sections.

\subsection{Governing equation}

Incremental strain-displacement relation in the curvilinear frame for curved beam undergoing combined bendingstretching is obtained from kinematic descriptions of the paper ${ }^{[13]}$ as given by

$$
\Delta \varepsilon_{s s}^{i}=\frac{1}{\left(1-\kappa^{i-1} n^{i-1}\right)}\left\{u_{s}^{\prime}+\frac{1}{2}\left(u_{s}^{\prime}\right)^{2}+\frac{1}{2}\left(u_{n}^{\prime}\right)^{2}-n^{i-1} u_{n}^{\prime \prime}\right\} .
$$

In the above equation, $\kappa^{i-1}$ represents the curvature of beam centre line. Using the above presented straindisplacement relation and linear material law $\Delta \sigma_{s s}^{i}=E \Delta \varepsilon_{s s}^{i}$, expression of strain energy of the curved beam with crosssectional width $b$ and thickness $h$ is derived as

$$
\begin{gathered}
U_{s}^{i}=\frac{E b}{2} \int_{-S_{L}^{i-1}}^{S_{R}^{i-1}} \int_{-h / 2}^{h / 2} \frac{1}{\left(1-\kappa^{i-1} n^{i-1}\right)}\left\{\left(u_{s}^{\prime}\right)^{2}+\frac{1}{4}\left(u_{s}^{\prime}\right)^{4}+\frac{1}{4}\left(u_{n}^{\prime}\right)^{4}+\left(n^{i-1}\right)^{2}\left(u_{n}^{\prime \prime}\right)^{2}+\left(u_{s}^{\prime}\right)^{3}\right. \\
\left.+\left(u_{s}^{\prime}\right)\left(u_{n}^{\prime}\right)^{2}-2 n^{i-1}\left(u_{s}^{\prime}\right)\left(u_{n}^{\prime \prime}\right)+\frac{1}{2}\left(u_{s}^{\prime}\right)^{2}\left(u_{n}^{\prime}\right)^{2}-n^{i-1}\left(u_{s}^{\prime}\right)^{2} u_{n}^{\prime \prime}-n^{i-1}\left(u_{n}^{\prime}\right)^{2} u_{n}^{\prime \prime}\right\} d n^{i-1} d s^{i-1} .
\end{gathered}
$$

Potential energy of externally applied end loads $\left(F_{L}^{i}\right.$ and $\left.F_{R}^{i}\right)$ and internal stress field of previous incremental step $\left(\sigma_{s s}^{i-1}\right)$ is given by

$$
\begin{gathered}
V_{s}^{i}=-\left.F_{L}^{i} \cos \left(\theta^{i-1}\right) u_{n}\right|_{-S_{L}^{i-1}}-\left.F_{L}^{i} \sin \left(\theta^{i-1}\right) u_{s}\right|_{-S_{L}^{i-1}}-\left.F_{R}^{i} \cos \left(\theta^{i-1}\right) u_{n}\right|_{S_{R}^{i-1}}-\left.F_{R}^{i} \sin \left(\theta^{i-1}\right) u_{s}\right|_{S_{R}^{i-1}} \\
+b \int_{-S_{L}^{i-1}}^{S_{R}^{i-1}} \int_{h / 2}^{h / 2} \sigma_{s s}^{i-1}\left\{u_{s}^{\prime}+\frac{1}{2}\left(u_{s}^{\prime}\right)^{2}+\frac{1}{2}\left(u_{n}^{\prime}\right)^{2}-n^{i-1} u_{n}^{\prime \prime}\right\} d n^{i-1} d s^{i-1}
\end{gathered}
$$

Following Ritz method, unknown displacement fields are approximated in normalized curvilinear coordinate $\left(\xi^{i-1}, \eta^{i-1}\right)$ as $u_{n}=\sum_{i=1}^{\mathrm{nn}} c_{1_{i}} \gamma_{i}\left(\xi^{i-1}\right)$ and $u_{s}=\sum_{i=1}^{\mathrm{nn}} c_{2_{i}} \beta_{i}\left(\xi^{i-1}\right)$. For the sake of simplicity in computation, origin of the normalized curvilinear frame $\left(\xi^{i-1}, \eta^{i-1}\right)$ is taken at left end of curved beam. Transformation relations of the normalized computational frame with the dimensional curvilinear frame are given by $\xi^{i-1}=\left(s^{i-1}+S_{L}^{i-1}\right) / S^{i-1}$ and $\eta^{i-1}=\left(n^{i-1}+h / 2\right) /$ $h$. With the approximated displacement fields, governing equation for incremental deformation behaviour of the curved beam system is derived through variational energy principle $\delta\left(U_{s}^{i}+V_{s}^{i}\right)=0$. Final algebraic form of the governing equation is presented as

$$
\left[\begin{array}{ll}
{\left[K_{11}\right]} & {\left[K_{12}\right]} \\
{\left[K_{21}\right]} & {\left[K_{22}\right]}
\end{array}\right]\left\{\begin{array}{l}
c_{1} \\
c_{2}
\end{array}\right\}=\left\{\begin{array}{l}
f_{1} \\
f_{2}
\end{array}\right\} .
$$

Expressions of stiffness matrix and load vector elements of the above equation are presented below. 


$$
\begin{aligned}
& {\left[K_{11}\right]=\sum_{j=1}^{n n} \sum_{l=1}^{n n} \frac{E A}{2\left(S^{i-1}\right)^{3}} \int_{0}^{1} \int_{0}^{1} \frac{1}{\left\{1-\kappa^{i-1} h\left(\eta^{i-1}-0.5\right)\right\}}\left[\left\{\left(\sum_{k=1}^{n n} c_{1_{k}} \gamma_{k}^{\prime}\right)^{2}+S^{i-1}\left(\sum_{k=1}^{n s} c_{2_{k}} \beta_{k}^{\prime}\right)+\left(\sum_{k=1}^{n s} c_{2_{k}} \beta_{k}^{\prime}\right)^{2}\right.\right.} \\
& \left.\left.-2 h\left(\eta^{i-1}-0.5\right)\left(\sum_{k=1}^{n n} c_{1_{k}} \gamma_{k}^{\prime \prime}\right)\right\} \gamma_{l}^{\prime} \gamma_{j}^{\prime}+2 h^{2}\left(\eta^{i-1}-0.5\right)^{2} \gamma_{l}^{\prime \prime} \gamma_{j}^{\prime \prime}-h\left(\eta^{i-1}-0.5\right)\left(\sum_{k=1}^{n n} c_{1_{k}} \gamma_{k}^{\prime}\right) \gamma_{l}^{\prime} \gamma_{j}^{\prime \prime}\right] d \eta^{i-1} d \xi^{i-1} \\
& +\frac{b h}{S^{i-1}} \int_{0}^{1} \int_{0}^{1} \sigma_{s s}^{i-1}\left(\xi^{i-1}, \eta^{i-1}\right) \gamma_{l}^{\prime} \gamma_{j}^{\prime} d \eta^{i-1} d \xi^{i-1} \\
& {\left[K_{12}\right]=\frac{E A}{2\left(S^{i-1}\right)^{3}} \sum_{j=1}^{n n} \sum_{l=1}^{n s} \int_{0}^{1} \int_{0}^{1} \frac{1}{\left\{1-\kappa^{i-1} h\left(\eta^{i-1}-0.5\right)\right\}}\left[S^{i-1}\left(\sum_{k=1}^{n n} c_{1_{k}} \gamma_{k}^{\prime}\right) \beta_{l}^{\prime} \gamma_{j}^{\prime}\right.} \\
& \left.-\left\{2 S^{i-1} h\left(\eta^{i-1}-0.5\right)+h\left(\eta^{i-1}-0.5\right)\left(\sum_{k=1}^{n s} c_{2_{k}} \beta_{k}^{\prime}\right)\right\} \beta_{l}^{\prime} \gamma_{j}^{\prime \prime}\right] d \eta^{i-1} d \xi^{i-1} \\
& {\left[K_{21}\right]=\frac{E A}{2\left(S^{i-1}\right)^{3}} \sum_{j=1}^{n s} \sum_{l=1}^{n n} \int_{0}^{1} \int_{0}^{1} \frac{1}{\left\{1-\kappa^{i-1} h\left(\eta^{i-1}-0.5\right)\right\}}\left[S^{i-1}\left(\sum_{k=1}^{n n} c_{1_{k}} \gamma_{k}^{\prime}\right) \gamma_{l}^{\prime} \beta_{j}^{\prime}\right.} \\
& \left.-\left\{2 S^{i-1} h\left(\eta^{i-1}-0.5\right)+h\left(\eta^{i-1}-0.5\right)\left(\sum_{k=1}^{n s} c_{2_{k}} \beta_{k}^{\prime}\right)\right\} \gamma_{l}^{\prime \prime} \beta_{j}^{\prime}\right] d \eta^{i-1} d \xi^{i-1} \text {. } \\
& {\left[K_{22}\right]=\sum_{j=1}^{n s} \sum_{l=1}^{n s} \frac{E A}{2\left(S^{i-1}\right)^{3}} \int_{0}^{1} \int_{0}^{1} \frac{1}{\left\{1-\kappa^{i-1} h\left(\eta^{i-1}-0.5\right)\right\}}\left[\left\{2\left(S^{i-1}\right)^{2}+\left(\sum_{k=1}^{n s} c_{2_{k}} \beta_{k}^{\prime}\right)^{2}+3 S^{i-1}\left(\sum_{k=1}^{n s} c_{2_{k}} \beta_{k}^{\prime}\right)+\left(\sum_{k=1}^{n n} c_{1_{k}} \gamma_{k}^{\prime}\right)^{2}\right.\right.} \\
& \left.\left.-h\left(\eta^{i-1}-0.5\right)\left(\sum_{k=1}^{n n} c_{1_{k}} \gamma_{k}^{\prime \prime}\right)\right\} \beta_{l}^{\prime} \beta_{j}^{\prime}\right] d \eta^{i-1} d \xi^{i-1}+\frac{b h}{S^{i-1}} \int_{0}^{1} \int_{0}^{1} \sigma_{s s}^{i-1}\left(\xi^{i-1}, \eta^{i-1}\right) \beta_{l}^{\prime} \beta_{j}^{\prime} d \eta^{i-1} d \xi^{i-1} \\
& \left\{f_{1}\right\}=\left.F_{L}^{i} \cos \left(\theta^{i-1}\right) \sum_{j=1}^{n n} \gamma_{j}\right|_{\xi^{i-1}=0}+\left.F_{R}^{i} \cos \left(\theta^{i-1}\right) \sum_{j=1}^{n n} \gamma_{j}\right|_{\xi^{i-1}=1}+\frac{b h^{2}}{S^{i-1}} \sum_{j=1}^{n n} \int_{0}^{1} \int_{0}^{1} \sigma_{s s}^{i-1}\left(\xi^{i-1}, \eta^{i-1}\right)\left(\eta^{i-1}-0.5\right) \gamma_{j}^{\prime \prime} d \eta^{i-1} d \xi^{i-1} . \\
& \left\{f_{2}\right\}=\left.F_{L}^{i} \sin \left(\theta^{i-1}\right) \sum_{j=1}^{n s} \beta_{j}\right|_{\xi^{i-1}=0}+\left.F_{R}^{i} \sin \left(\theta^{i-1}\right) \sum_{j=1}^{n s} \beta_{j}\right|_{\xi^{i-1}=1}-b h \sum_{j=1}^{n s} \int_{0}^{1} \int_{0}^{1} \sigma_{s s}^{i-1}\left(\xi^{i-1}, \eta^{i-1}\right) \beta_{j}^{\prime} d \eta^{i-1} d \xi^{i-1}
\end{aligned}
$$

\subsection{Deflection profile}

Governing equation of the incremental curved beam problem, as presented in Equation (7), contains set of nonlinear algebraic equations. The nonlinear equation set is solved iteratively in the computational environment of MATLAB $^{\circledR}$ software for unknown coefficients $\left(c_{1}\right.$ and $\left.c_{2}\right)$. The iterative numerical scheme is adopted from the paper [13], and is not described in detail here to maintain brevity. Number of functions for the approximated bending and stretching displacement fields are taken as 5. Start functions for approximations of both the displacement fields are selected as $\left(\xi^{i-1}-\xi_{O}^{i-1}\right)^{2}$ through satisfaction of geometric boundary conditions (Equation $(1,2)$ ), where $\xi_{O}^{i-1}$ is normalized 
coordinate of the origin. Once the unknown coefficients are obtained, displacement fields $u_{n}$ and $u_{s}$ become known with respect to body fitted frame. The displacement fields are transformed from body embedded curvilinear frame to global Cartesian frame using the transformation relation of Equation (3), which finally yields deformed profile as

$$
\left\{\begin{array}{l}
x^{i} \\
y^{i}
\end{array}\right\}=\left\{\begin{array}{l}
x^{i-1} \\
y^{i-1}
\end{array}\right\}+\left[\begin{array}{cc}
\cos \left(\theta^{i-1}\right) & -\sin \left(\theta^{i-1}\right) \\
\sin \left(\theta^{i-1}\right) & \cos \left(\theta^{i-1}\right)
\end{array}\right]\left\{\begin{array}{l}
u_{s} \\
u_{n}
\end{array}\right\} .
$$

\section{Theoretical results and comparison}

Importing no-load geometry of the specimen from the [29] and equivalent end forces due to clamping from Table 2, deflection profiles of the four curved beam systems are computed up to maximum applied load $\left(F_{W}\right)$ of $500 \mathrm{~N}$. The theoretical deflection profiles are interpolated at the eight experimental load values $\left(F_{W}\right)$ and compared with the corresponding experimental results. Comparison plots of deflection profiles for the concave system under $3 \mathrm{~kg}-\mathrm{m}$ and 14 kg-m clamping torque are presented in Figure 5(a1) and (a2) respectively. Whereas, such comparison plots for the convex system are shown in Figure 5(b1) and (b2). The comparison plots in Figure 5 clearly show that the theoretical and experimental results are matching quite well for the concave system under both the clamping torques at all load levels. However, for the convex system, the theoretical and experimental results are matching well at the lower load levels but discrepancy between them increases with applied load.

(a1)

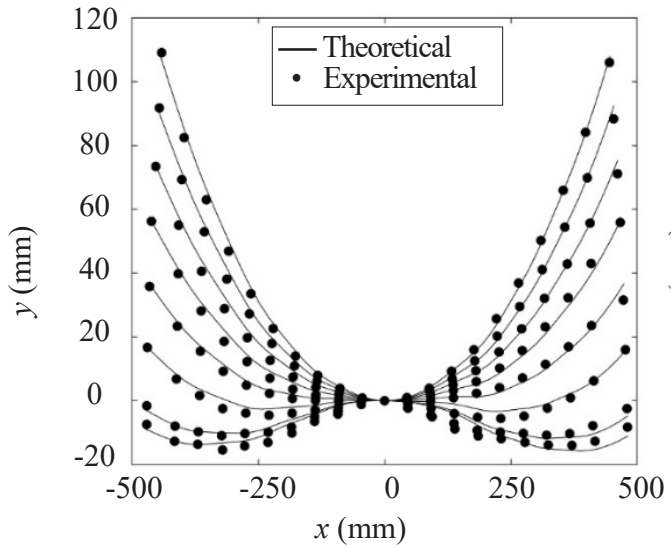

(b1)

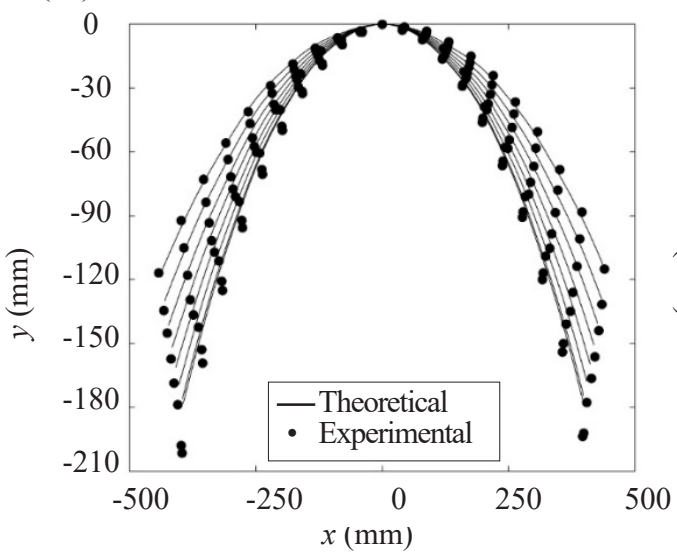

(a2)

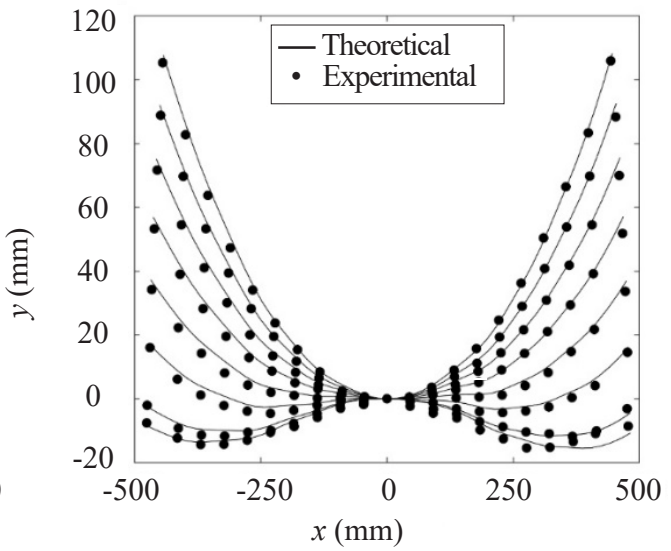

(b2)

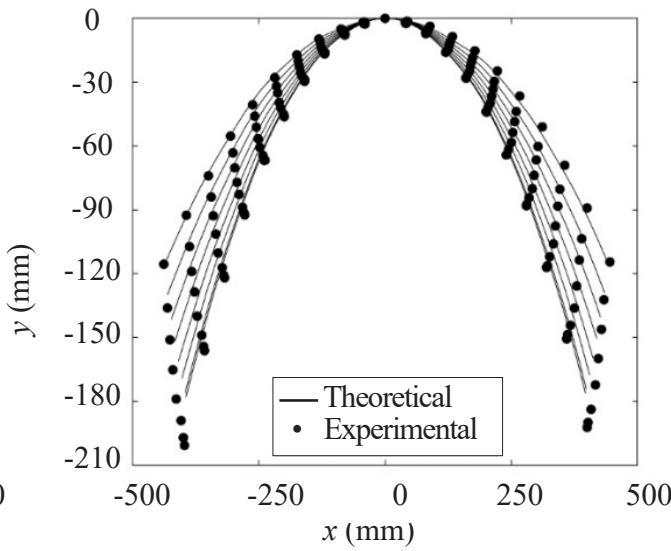

Figure 5. Deflection profiles of (a\#) concave and (b\#) convex curved beam system under (\#1) $3 \mathrm{~kg}-\mathrm{m}$ and (\#2) $14 \mathrm{~kg}-\mathrm{m}$ clamping torque (geometric and material parameters: $\mathrm{b}=38.5 \mathrm{~mm}$, $\left.\mathrm{h}=6.25 \mathrm{~mm}, \mathrm{~L}^{0}=878.4 \mathrm{~mm}, \mathrm{~S}^{0}=921.8 \mathrm{~mm}, \mathrm{E}=210 \mathrm{GPa}\right)$ 
Deformation characteristics of the curved beam systems are studied further in detail through tip deflections $\left(\delta_{L}\right.$ and $\left.\delta_{R}\right)$ and change in horizontal span $\left(\Delta L=L-L^{0}\right)$. Observations on the deformation measures are made through both theoretical and experimental results, and hence the investigations also provide comparison studies as well. Variations of the left tip deflection $\left(\delta_{L}\right)$ with applied load $\left(F_{W}\right)$ for the concave system under $3 \mathrm{~kg}-\mathrm{m}$ and $14 \mathrm{~kg}-\mathrm{m}$ clamping torques are presented in Figure 6(a1) and (a2) respectively. Whereas, load-deflection behaviours of the left tip for the convex system are shown in Figure 6(b1) and (b2). Similarly, load-deflection behaviours of the right tip for the concave and convex systems under both $3 \mathrm{~kg}-\mathrm{m}$ and $14 \mathrm{~kg}-\mathrm{m}$ clamping torques are shown in Figure 7. Whereas, variations of change in horizontal span $(\Delta L)$ with applied load $\left(F_{W}\right)$ for the four curved beam systems are presented in Figure 8.

As clearly seen from Figures 6 and 7, tip deflections $\left(\delta_{L}\right.$ and $\left.\delta_{R}\right)$ of the concave systems show softening type nonlinearity against applied load $\left(F_{W}\right)$. Whereas, the convex systems possess hardening type nonlinearity in terms of tip deflections $\left(\delta_{L}\right.$ and $\left.\delta_{R}\right)$ against applied load $\left(F_{W}\right)$. Contrary behaviours of the concave and convex curved beam systems for horizontal span changes $(\Delta L)$ are observed in Figure 8 . Here, the concave systems possess hardening type nonlinearity in variations of changes in span $(\Delta L)$ with applied load $\left(F_{W}\right)$. Whereas, changes in span $(\Delta L)$ for the convex systems show softening type nonlinearity against applied load $\left(F_{W}\right)$. Comparisons of deformation characteristics $\left(\delta_{L}, \delta_{R}\right.$, and $\Delta L$ ) between the theoretical and experimental results in Figures 6-8 clearly show better matching for the concave systems compared to the convex ones. However, trends of the deformation measures of the curved beam systems are almost same for both theoretical and experimental results.
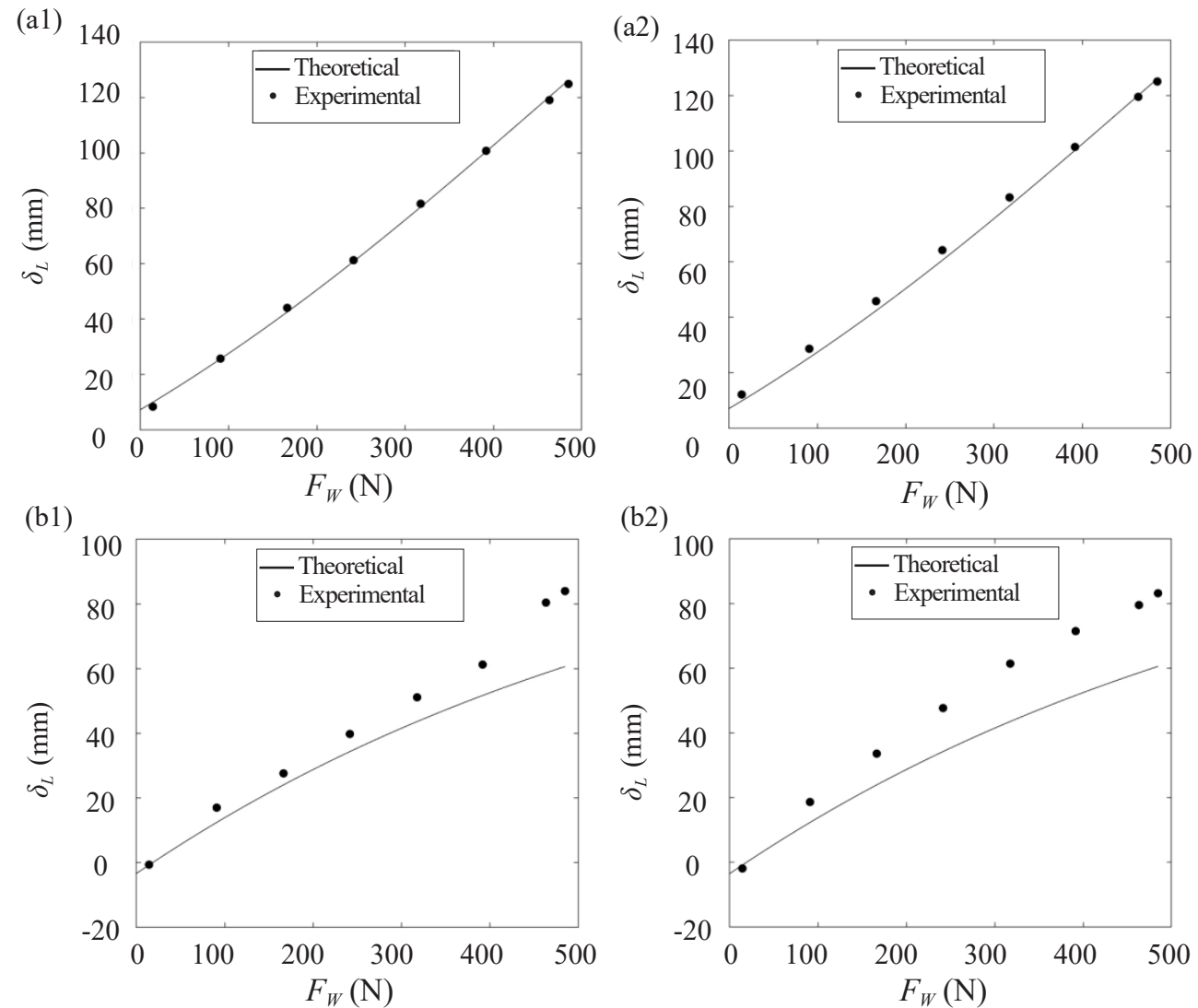

Figure 6. Load-deflection behaviour of the left tip for (a\#) concave and (b\#) convex curved beam system under (\#1) $3 \mathrm{~kg}-\mathrm{m}$ and (\#2) $14 \mathrm{~kg}-\mathrm{m}$ clamping torque 
(a1)

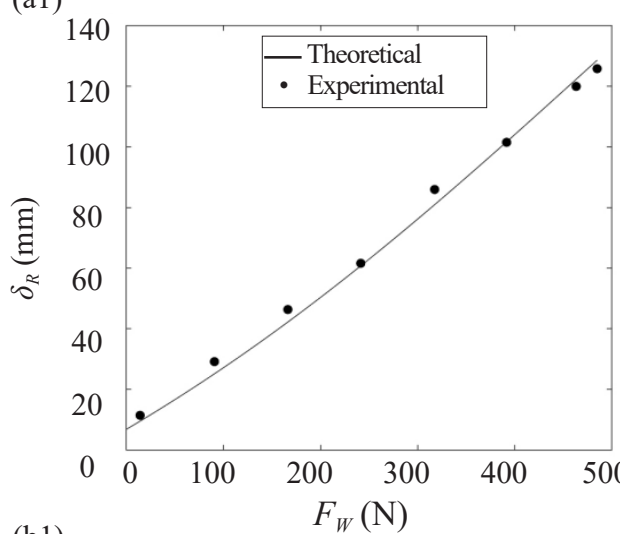

(b1)

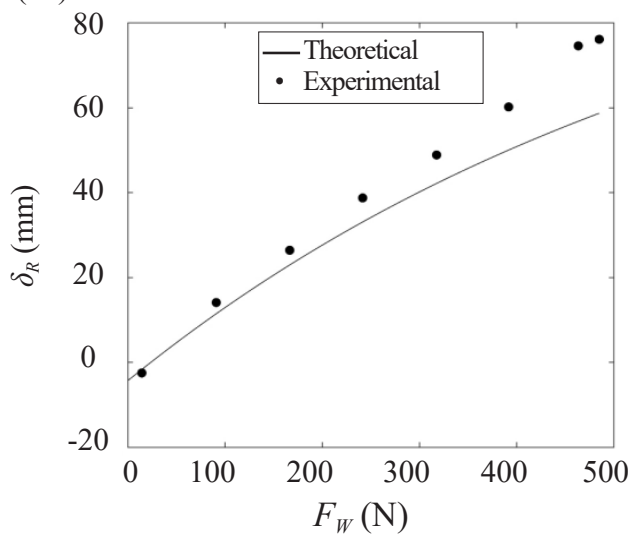

(a2)

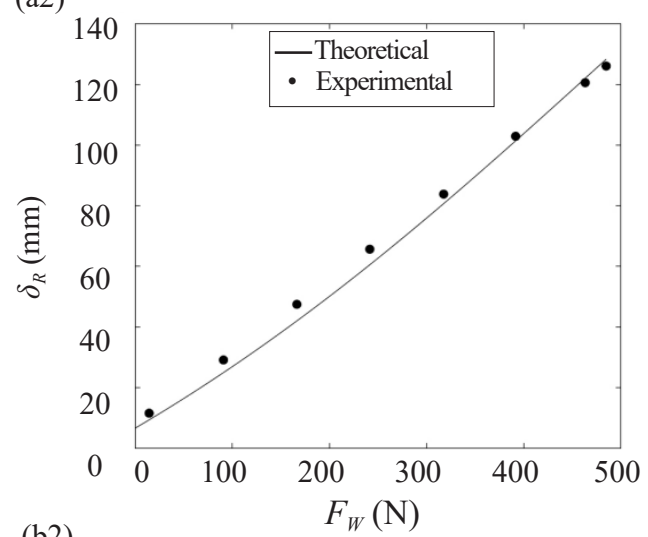

(b2)

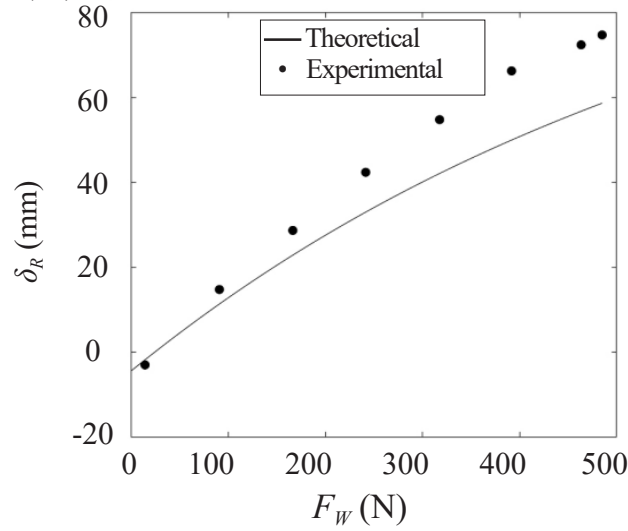

Figure 7. Load-deflection behaviour of the right tip for (a\#) concave and (b\#) convex curved beam system under (\#1) $3 \mathrm{~kg}-\mathrm{m}$ and (\#2) $14 \mathrm{~kg}-\mathrm{m}$ clamping torque

(a1)

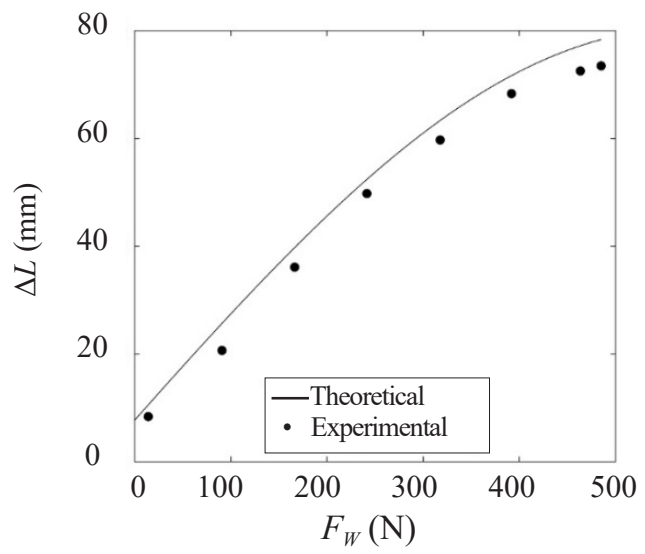

(a2)

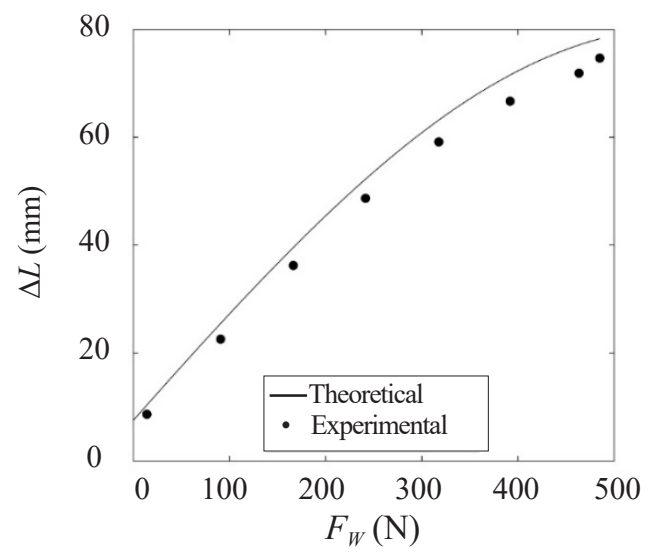


(b1)

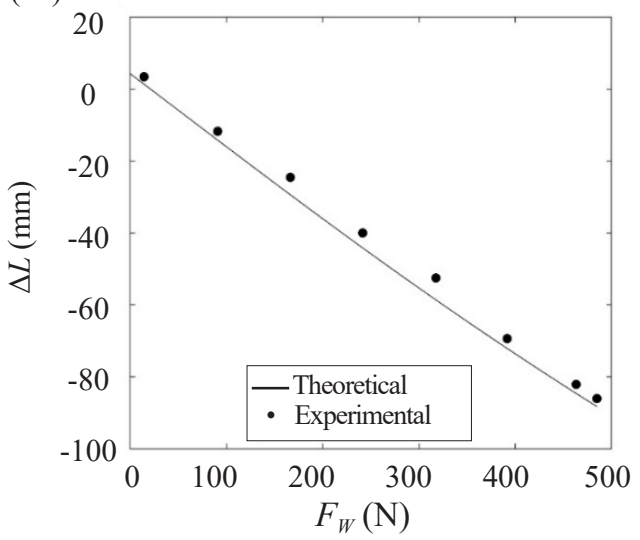

(b2)

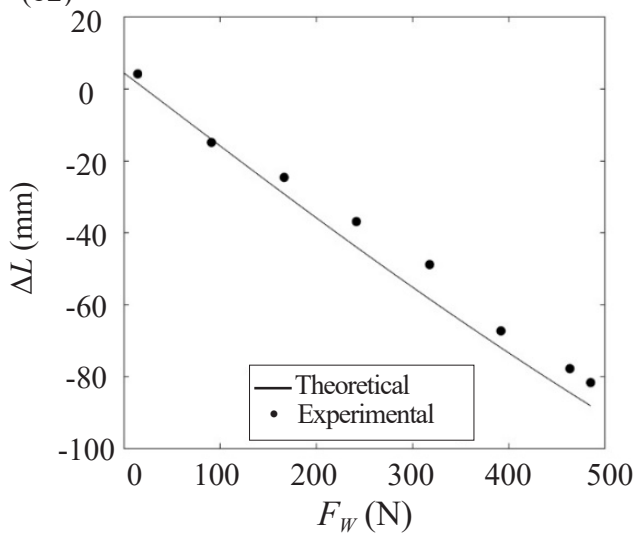

Figure 8. Change in span with load for ( $\mathrm{a} \#)$ concave and $(\mathrm{b} \#)$ convex curved beam system under (\#1) $3 \mathrm{~kg}-\mathrm{m}$ and (\#2) $14 \mathrm{~kg}-\mathrm{m}$ clamping torque

One of the major discrepancy between the theoretical model and the actual experimental system lies in modelling of the clamping zone as point. Whereas, the experimental curved bean system contains clamping zone of finite length. Clamping of the curved beam specimen not only induces a locked-up moment but also imparts a clamping force nonuniformly distributed over the finite clamping zone. Hence, in addition to some deflections caused by locked-up moment, the clamping force causes local deformation at the clamping zone. Increment of discrepancy with applied load and for convex system compared to concave one clearly indicates towards another limitation of the theoretical model. Actually locked-up moment and local deformation produced by finite clamping depend on magnitude and combination of applied loadings. Whereas, the theoretical model does not consider such deformation and loading combination dependent effect of clamping. Consideration of local deformation due to distributed clamping force in addition to locked-up moment leads toward a very complicated combined displacement and stress based mathematical model. In addition, incorporation of deformation and loading combination dependency of such clamping effect further complicates the analysis. Though considerations of the mentioned complicating effects may leads towards more rigorous simulation, the present theoretical model well captures deformation characteristics of the curved beam system without considering such complications. Hence, the developed theoretical model may be of interest from engineering perspective, in analysis of many practical curved beam structures with complicating system parameters.

\section{Conclusions}

As a result of provided theoretical and experimental analysis of the large deflection behaviour of clamped curved beam under finite clamping and combined bending-stretching loads, two different combinations of bending-stretching loadings are created under vertical end loads by clamping the experimental specimen with vertically concave and convex orientations. At each of the specimen settings, experimental observations are carried out under two different clamping torques. Effects of finite clamping and loading combinations are obtained through post-processing experimental results. A theoretical model for large deformation characteristics of the experimental system is developed based on incremental Lagrangian approach in body fitted curvilinear frame. Effect of finite clamping is incorporated in the theoretical model through equivalent end loads based on the experimental observations. In addition, geometrically nonlinear effects coming from combined bending-stretching, non-uniform initial geometry, asymmetry in geometry about clamping location, etc., are also considered in the theoretical model. The theoretical model is compared with experiment and some insight characteristics of clamped curved beam system are noted. The developed easy to implement model not only captured deformation characteristics of the considered experimental system but addressed a frequently encountered issue on complicating local deformation of practical beam like structures at boundaries. 


\section{Acknowledgements}

The first author would like to acknowledge the financial support in form of research fellowship by state government fellowship scheme of Jadavpur University, West Bengal, India. The authors would also like to thank the anonymous reviewers for their valuable comments and suggestions that have greatly improved an earlier version of the paper to its present form.

\section{Conflict of interest}

The authors declare no conflict of interest.

\section{Nomenclature}

$b$

$\{c\}$

E

$\{f\}$

$F_{C L}, F_{C R}$

$F_{L}, F_{R}$

$F_{W}$

$h$

[K]

$L$

$O_{s n}$

$O_{x y}$

$S$

$u_{n}, u_{s}$

$u_{x}, u_{y}$

$U_{s}$

$V_{s}$

$\beta, \gamma$

$\delta_{C L}, \delta_{C R}$

$\delta_{L}, \delta_{R}$

$\delta_{W L}, \delta_{W R}$

$\Delta L$

$\Delta \varepsilon_{S S}$

$\Delta \sigma_{s S}$

$\theta$

$\kappa$

Superscripts

0

i-1

$i$

Subscripts

L

$R$
Width of rectangular beam cross-section

Unknown coefficient vector

Young's modulus

Load vector

Equivalent end loads due to clamping at left and right ends

Total vertical loads at left and right ends

Externally applied load

Thickness of rectangular beam cross-section

Thickness of rectangular beam cross-section

Horizontal span of curved beam

Body fitted curvilinear frame

Global Cartesian frame

Arch length of curved beam

Bending and stretching displacement fields in body embedded frame

Horizontal and vertical components of displacement field in global frame

Strain energy

Potential energy

Set of functions in stretching and bending field approximations

Deflections of left and right tip due to clamping only

Total deflections of left and right tip

Deflections of left and right tip due to external load only

Change in horizontal span

Incremental axial strain

Incremental axial stress

Slope of beam centre line

Curvature of beam centre line

No-load condition

Previous incremental load step

Current incremental load step

Left part of curved beam

Right part of curved beam 


\section{References}

[1] I.H. Shames and C.L. Dym, Energy and Finite Element Methods in Structural Mechanics. New York: Hemisphere Publishing Corporation, 1985.

[2] C.M. Wang, K.Y. Lam, X.Q. He and S. Chucheepsakul, "Large deflections of an end supported beam subjected to a point load," International Journal of Non-Linear Mechanics, vol. 32, no. 1, pp. 63-72, 1997.

[3] K.J. Bathe and S. Bolourchi, "Large displacement analysis of three-dimensional beam structures," International Journal for Numerical Methods in Engineering, vol. 14, no. 7, pp. 961-986, 1979.

[4] K. Washizu, "Some considerations on a naturally curved and twisted slender beam," Journal of Mathematics and Physics, vol. 43 no. 1-4, pp. 111-116, 1964.

[5] J.C. Simo and L. Vu-Quoc, "A geometrically-exact rod model incorporating shear and torsion-warping deformation," International Journal of Solids and Structures, vol. 27 no.3, pp. 371-393, 1991.

[6] M. Batista, "Large deflections of a beam subject to three-point bending," International Journal of Non-Linear Mechanics, vol. 69, pp. 84-92, 2015.

[7] X.F. Li and K.Y. Lee, "Effect of horizontal reaction force on the deflection of short simply supported beams under transverse loadings," International Journal of Mechanical Sciences, vol. 99, pp. 121-129, 2015.

[8] A. Mohyeddin and A. Fereidoon, "An analytical solution for the large deflection problem of Timoshenko beams under three-point bending," International Journal of Mechanical Sciences, vol. 78, pp. 135-139, 2014.

[9] S. Ghuku and K.N. Saha, "An experimental study on stress concentration around a hole under combined bending and stretching stress field," Procedia Technology, vol. 23, pp. 20-27, 2016.

[10] F. Mujika, "On the effect of shear and local deformation in three-point bending tests," Polymer Testing, vol. 26, no. 7, pp. 869-877, 2007.

[11] S. Mondal, S. Ghuku and K.N. Saha, "Effect of clamping torque on large deflection static and dynamic response of a cantilever beam: An experimental study," International Journal of Engineering and Technologies, vol.15, pp. 1-16, 2018.

[12] S. Ghuku and K. Saha, "Stiffness analysis of leaf spring system under large deformation," In Proceedings of the Institution of Mechanical Engineers, Part C: Journal of Mechanical Engineering Science, vol. 234, no. 12, pp. 2487-2508, 2020.

[13] S. Ghuku and K.N. Saha, "A parametric study on geometrically nonlinear behavior of curved beams with single and double link rods, and supported on moving boundary," International Journal of Mechanical Sciences, vol. 161, pp. 105065, 2019. Available: https://doi.org/10.1016/j.ijmecsci.2019.105065 [Aug. 20, 2020].

[14] M. Rezaiee-Pajand and A.R. Masoodi, "Stability analysis of frame having FG tapered beam-column," International Journal of Steel Structures, vol. 19, no. 2, pp. 446-468, 2019.

[15] M. Rezaiee-Pajand, A.R. Masoodi and M. Bambaeechee, "Tapered beam-column analysis by analytical solution," In Proceedings of the Institution of Civil Engineers-Structures and Buildings, vol. 172, no. 11, pp. 789-804, 2019.

[16] W. Lacarbonara and H. Yabuno, "Refined models of elastic beams undergoing large in-plane motions: Theory and experiment," International Journal of Solids and Structures, vol. 43, no.17, pp. 5066-5084, 2006.

[17] W. Lestari and S. Hanagud, "Nonlinear vibration of buckled beams: Some exact solutions," International Journal of Solids and Structures, vol. 38, no.26-27, pp. 4741-4757, 2001.

[18] S.Q. Ye, X.Y. Mao, H. Ding, J.C. Ji and L.Q. Chen, "Nonlinear vibrations of a slightly curved beam with nonlinear boundary conditions," International Journal of Mechanical Sciences, vol. 168, pp. 105294, 2020. Available: https:// doi.org/10.1016/j.ijmecsci.2019.105294 [Aug. 20, 2020].

[19] T. Beléndez, C. Neipp and A. Beléndez, "Large and small deflections of a cantilever beam," European Journal of Physics, vol. 23, no. 3, pp. 371-379, 2002.

[20] M. Dado and S. Al-Sadder, "A new technique for large deflection analysis of non-prismatic cantilever beams," Mechanics Research Communications, vol. 32, no. 6, pp. 692-703, 2005.

[21] N.N. Bui, M. Ngo, M. Nikolic, D. Brancherie and A. Ibrahimbegovic, "Enriched Timoshenko beam finite element for modeling bending and shear failure of reinforced concrete frames," Computers \& Structures, vol. 143, pp. 9-18, 2014.

[22] A. Mitra, P. Sahoo and K. Saha, "Large displacement of crossbeam structure through energy method," International Journal of Automotive and Mechanical Engineering, vol. 5, pp. 520-544, 2012.

[23] A. Ibrahimbegović and F. Frey, "Finite element analysis of linear and non-linear planar deformations of elastic initially curved beams," International Journal for Numerical Methods in Engineering, vol. 36, no. 19, pp. 32393258, 1993. 
[24] A. Ibrahimbegović, “On finite element implementation of geometrically nonlinear Reissner's beam theory: Threedimensional curved beam elements," Computer Methods in Applied Mechanics and Engineering, vol. 122, no. 1-2, pp. 11-26, 1995.

[25] M. Rezaiee-Pajand, N. Rajabzadeh-Safaei and A.R. Masoodi, “An efficient mixed interpolated curved beam element for geometrically nonlinear analysis," Applied Mathematical Modelling, vol. 76, pp. 252-273, 2019.

[26] M. Liao, G. Xu and Y.B. Yang, "Geometrically nonlinear quadrature element analysis of spatial curved beams," Engineering Structures, vol. 209, pp. 110004, 2020. Available: https://doi.org/10.1016/j.engstruct.2019.110004 [Aug. 20, 2020].

[27] S. Ghuku and K.N. Saha, "A review on stress and deformation analysis of curved beams under large deflection," International Journal of Engineering and Technologies, vol. 11, pp. 13-39, 2017.

[28] C. Meier, A. Popp and W.A. Wall, "Geometrically exact finite element formulations for slender beams: KirchhoffLove theory versus Simo-Reissner theory," Archives of Computational Methods in Engineering, vol. 26, no. 1, pp. $163-243,2019$.

[29] S. Ghuku and K.N. Saha, "A master leaf spring under combined bending and stretching: An experimental study," in Proceedings of 61st congress of the Indian Society of Theoretical and Applied Mechanics (ISTAM 2016), 2016, pp. 541. 